\title{
Adaptive Changes in Transmembrane Transport and Metabolism of Triiodothyronine in Perfused Livers of Fed and Fasted Hypothyroid and Hyperthyroid Rats
}

\author{
Marion de Jong, Roel Docter, Hans van der Hoek, Eric P. Krenning, and Georg Hennemann
}

\begin{abstract}
The transport and subsequent metabolism of triiodothyronine $\left(T_{3}\right)$ were studied in isolated perfused livers of euthyroid, hypothyroid, and hyperthyroid rats, both fed and 48-hour-fasted. $T_{3}$ kinetics (transport and metabolism) during perfusion were evaluated by a two-pool model, whereas the metabolism of $T_{3}$ was also investigated by determination of $T_{3}$ breakdown products by chromatography of medium and bile. For comparison of groups, metabolism was corrected for differences in transport. Transport parameters in fed hypothyroid livers were not significantly changed as compared with euthyroid livers, whereas metabolism was decreased. In fed hyperthyroid livers, fractional transfer rate constants for influx $\left(k_{21}\right)$ and efflux $\left(k_{12}\right)$ were decreased and metabolism, corrected for differences in intracellular mass transfer, was increased. Furthermore, for transport in hyperthyroid livers it was shown that only total mass transfer (TMT) into the metabolizing liver compartment (not into the nonmetabolizing liver compartment) was decreased. Transport and metabolic parameters in fasted hypothyroid livers were decreased as compared with euthyroid fed livers. In fasted hyperthyroid livers, transport and metabolism were not significantly different as compared with that in euthyroid fed livers, so transport was increased versus hyperthyroid fed livers. It appeared therefore that fasting normalized the effects of hyperthyroidism on both the transport and metabolic processes of $T_{3}$ in the liver. The present study demonstrates normal transport and decreased metabolism in livers of hypothyroid fed rats and decreased transport and increased metabolism in livers of hyperthyroid fed rats. In livers of hypothyroid fasted rats transport and metabolism were decreased, whereas in livers of hyperthyroid fasted rats transport and metabolism were not significantly different from that in euthyroid fed livers. These changes might favor tissue euthyroidism despite the altered thyroid and nutritional state, and can therefore be seen as adaptation mechanisms to these altered states at the tissue level.
\end{abstract}

Copyright $\odot 7994$ by W.B. Saunders Company

$\mathbf{T}$ HE EFFECTS OF hyperthyroidism and hypothyroidism on thyroid hormone metabolism in vitro and in vivo have heen extensively investigated. ${ }^{1-5}$ However, these effects are as yet incompletely understood. In hyperthyroid humans, both decreased ${ }^{6}$ and increased ${ }^{7}$ metabolic rates for thyroid hormones are reported, whereas hypothyroid humans are reported to have an increased fractional conversion rate of thyroxine $\left(\mathrm{T}_{4}\right)$ to triiodothyronine $\left(\mathrm{T}_{3}\right) .^{7.8}$ Conversion of thyroid hormone mostly takes place by deiodination and conjugation reactions. ${ }^{9}$ Deiodination of $T_{4}, T_{3}$, and reverse $T_{3}\left(\mathrm{rT}_{3}\right)$ is catalyzed by at least three different deiodinating enzymes (type I. II, and III) located in different tissues..$^{10,11}$ The liver quantitatively plays an important role in deiodination because of the presence of type I deiodinase. ${ }^{10}$ Hyperthyroidism increases deiodination of iodothyronines by rat liver homogenates. ${ }^{4,5}$ In hypothyroidism, rat tissue deiodinase activities for all iodothyronines were decreased, as was found in homogenates and tissue-slice studies. 4.5 However, the latter data were obtained in broken-cell preparations, which have several drawbacks. Sulfation, for example, occurs only in intact cells and greatly potentiates deiodination, especially of $T_{3 .}{ }^{9}$ However, in intact isolated liver cell cultures, there is no normal relationship between transport of iodothyronines from the plasma into the cells and subsequent metabolism. Intact liver perfusion is therefore presumably the most physiological in vitro technique, since in this system the importance of other processes in thyroid hormone metabolism, such as transport over the cell membrane, can be investigated.

As for transport, we have demonstrated the presence of specific energy-dependent cellular uptake mechanisms for $T_{4}, T_{3}$ and $r_{3}$ in rat hepatocytes. ${ }^{12-14}$ According to kinetic experiments, $T_{4}$ and $\mathrm{rT}_{3}$ appear to enter the cell by a common pathway, which is different from that for $T_{3}$.
Evidence has been presented for two distinct pathways for $\mathrm{T}_{4}$ and $\mathrm{T}_{3}$ transport in the perfused rat live $\mathrm{r}^{15}$ and in vivo in the human liver ${ }^{16}$ as well. Recently, we reported a discrimination between transport to a nonmetabolizing, presumably extracellular liver compartment and transport into an intracellular, metabolizing liver compartment in the perfused rat liver. ${ }^{17,18}$

To investigate whether changes in plasma membrane transport or in subsequent metabolism of $T_{3}$ occur in hyperthyroidism and hypothyroidism, we studied these processes using a recirculating rat liver perfusion system. The effects of fasting in combination with hypothyroidism and hyperthyroidism were also investigated, since little attention has been paid until now to the influence of the nutritional state on thyroid hormone handling during hypothyroidism and hyperthyroidism.

\section{MATERIALS AND METHODS}

\section{Materials}

Male Wistar rats weighing 200 to $250 \mathrm{~g}$ were used in all experiments. Rats were made hyperthyroid by daily intraperitoneal injection of $\mathrm{T}_{4}(10 \mu \mathrm{g} / 100 \mathrm{~g}$ body weight $)$ for 15 days. Hypothyroidism was induced by addition of $0.05 \%$ mercaptomethylimidazole to

From the Departments of Internal Medicine III and Nuclear Medicine, Medical Faculty, Erasmus University, Rotterdam, The Netherlands.

Submitted May 25, 1993; accepted February 14, 1994.

Supported in part by the Foundation for Medical Research MEDIGON (900-540-191).

Address reprint requests to Marion de Jong, PhD. Department of Internal Medicine III, University Hospital Dijkzigt, Dr. Molewaterplein 40, 3015 GD Rotterdam. The Netherlands.

Copyright 1994 by W.B. Saunders Company

0026-0495/94/4311-0005\$03.00/0 
the drinking water for at least 3 weeks. Hyperthyroidism and hypothyroidism were confirmed by estimation of $\mathrm{T}_{4}$ and thyrotropin (TSH) levels in plasma by radioimmunoassay $\left(\mathrm{T}_{4}\right)$ and an ultrasensitive TSH assay of which the lower limit of detection was $0.18 \mathrm{ng} \mathrm{TSH} / \mathrm{mL}$. In studies on the effect of fasting, food was withdrawn for 48 hours, but free access to drinking water was maintained.

$\mathrm{L}-\mathrm{T}_{3}$ was obtained from Sigma (St Louis, MO) and $\left[3^{\prime}-{ }^{125} 1\right] \mathrm{T}_{3}$ (specific activity $>1,200 \mu \mathrm{Ci} / \mu \mathrm{g}$ ) from Amersham International (Aylesbury, UK). All other reagents were of the highest purity commercially available.

\section{Experimental Procedures}

Livers were isolated and perfused in a recirculating system at $37^{\circ} \mathrm{C}$. essentially as described by Meijer et al. ${ }^{19}$ The medium used in all experiments was $150 \mathrm{~mL}$ Krebs-Ringer medium with addition of $1 \%$ or $4 \%$ bovine serum albumin (BSA). The medium was gassed with carbogen $\left(95 \% \mathrm{O}_{2}, 5 \% \mathrm{CO}_{2}, 400 \mathrm{~mL} / \mathrm{min}\right)$. The functional state of the organ was monitored by its outer appearance and measurement of medium flow $(40 \mathrm{~mL} / \mathrm{min})$, bile flow $(\sim 0.7$ $\mathrm{mL} / \mathrm{h}$ ), $\mathrm{pH}$ of the medium (7.43), and enzyme release (lactate dehydrogenase, aspartate aminotransferase, and alanine aminotransferase) into the perfusion medium. In short, after isolation the liver was preperfused for 0.5 hours. The experiments were started by the addition of $T_{3}(300 \mathrm{pmol}$ to media with $1 \% \mathrm{BSA}$ or 1,200 pmol to media with $4 \%$ BSA) and ${ }^{125} \mathrm{I}_{-} \mathrm{T}_{3}$ to the medium (time 0 ). Medium aliquots of $0.5 \mathrm{~mL}$ were taken at $0.5,1,2,3,4,5,10,15,20$, $25,30,40,50$, and 60 minutes. Bile was collected at 10-minute intervals. Medium and bile samples were stored at $-20^{\circ} \mathrm{C}$ until further analysis. For analysis of medium aliquots, mixtures were prepared consisting of $0.5 \mathrm{~mL}$ medium and $0.5 \mathrm{~mL} 1$-mol/ $\mathrm{L} \mathrm{HCl}$. These were applied to small Sephadex LH-20 columns (bed volume, $1 \mathrm{~mL}$ ) equilibrated with $3 \mathrm{~mL} 0.1-\mathrm{mol} / \mathrm{L} \mathrm{HCl}$. Iodide was eluted with $3 \times 1 \mathrm{~mL} 0.1-\mathrm{mol} / \mathrm{L} \mathrm{HCl}$, and $\mathrm{T}_{3}$ glucuronide $\left(\mathrm{T}_{3} \mathrm{G}\right), \mathrm{T}_{3}$ sulfate $\left(\mathrm{T}_{3} \mathrm{~S}\right)$, and remaining $\mathrm{T}_{3}$ with $8 \times 1 \mathrm{~mL}$ sodium acetate $(0.1$ $\mathrm{mol} / \mathrm{L}, \mathrm{pH} 4), 6 \times 1 \mathrm{~mL} \mathrm{H}_{2} \mathrm{O}$, and $3 \times 1 \mathrm{~mL} \mathrm{NaOH}(0.1$ $\mathrm{mol} / \mathrm{L}) /$ ethanol $50: 50(\mathrm{vol} / \mathrm{vol})$, respectively. Fractions of $1 \mathrm{~mL}$ were collected and counted for radioactivity. Bile was also analyzed on Sephadex LH-20 after addition of $950 \mu \mathrm{L} 0.1-\mathrm{mol} / \mathrm{L} \mathrm{HCl}$ to a $50-\mu \mathrm{L}$ aliquot. The same chromatographic procedure used for medium analysis was followed. Free $\mathrm{T}_{3}\left(\mathrm{FT}_{3}\right)$ concentrations in medium aliquots were determined by equilibrium dialysis according to the method of Sterling and Brenner. ${ }^{20}$ The percentage of $\mathrm{FT}_{3}$ in medium was not significantly different in all the fed and fasted groups $(2.23 \%$ to $2.30 \%)$

For analysis of $T_{3}$ kinetics. the tracer $T_{3}$ disappearance curve from the medium of each experiment was fitted to a twoexponential model, as described by Docter et al. ${ }^{17}$ Using this model consisting of a medium and a liver pool, fractional transfer rate constants for influx $\left(k_{21}\right)$ and efflux $\left(k_{12}\right)$, the fractional disposal rate constant $\left(k_{12}\right)$, total mass transfer (TMT), and the total disposal were calculated. Disposal could be corrected for differences in TMT into the intracellular liver compartment, resulting in the equation metabolic capacity $=$ disposal $/$ intracellular mass transfer.

With the aid of experiments with $1 \%$ and $4 \%$ BSA in the medium and using the two-pool model, it is possible to discriminate between transport of $\mathrm{T}_{3}$ to a nonmetabolizing. presumably extracellular, liver compartment and transport into the intracellular liver compartment, as described earlier. ${ }^{17}$ During the perfusion with $1 \mathrm{C}^{\prime}$ BSA,

$$
\mathrm{TMT}_{\{1 \cdots \mathrm{BSA})}=\mathrm{X}+\mathrm{Y}
$$

where $\mathrm{X}$ is the transport of $\mathrm{T}_{3}$ to the intracellular compartment, $\mathrm{Y}$
Table 1. TSH and $T_{4}$ Serum Levels in Euthyroid, Hypothyroid, and Hyperthyroid Rats

\begin{tabular}{lccc} 
& $\begin{array}{c}\text { Euthyroid } \\
(\mathrm{n}=7)\end{array}$ & $\begin{array}{c}\text { Hypothyroid } \\
(\mathrm{n}=8)\end{array}$ & $\begin{array}{c}\text { Hyperthyroid } \\
(\mathrm{n}=4)\end{array}$ \\
\hline $\mathrm{TSH}(\mathrm{ng} / \mathrm{mL})$ & $1.6 \pm 0.3$ & $13.8 \pm 1.3^{*}$ & $0.4 \pm 0.04^{*}$ \\
$\mathrm{~T}_{4}(\mathrm{nmol} / \mathrm{L})$ & $54 \pm 4$ & $8 \pm 3^{*}$ & $154 \pm 14^{*}$ \\
\hline
\end{tabular}

$* P<.001 v$ euthyroid.

is the transport of $T_{3}$ to the extracellular compartment. and TMT is the total amount of $T_{3}$ transported to the liver during the perfusion. Since $\mathrm{X}$ is linearly related to medium $\mathrm{FT}_{3}$ and $\mathrm{Y}$ is linearly related both to medium $\mathrm{FT}_{3}$ and the medium albumin concentration, ${ }^{17.18}$ it follows that during the perfusion with $4 \% \mathrm{BSA}$ in the medium

$$
\begin{aligned}
\mathrm{TMT}_{(4 ; \mathrm{BSA})}=\left[\mathrm{FT}_{3(4 ; \mathrm{BSA})} / \mathrm{FT}_{3(1 ; \mathrm{BSA})}\right] \mathrm{X} \\
+4\left[\mathrm{FT}_{3(4 ; \mathrm{BSA})} / \mathrm{FT}_{3(1) \mathrm{BSA})}\right] \mathrm{Y} .
\end{aligned}
$$

In this way two equations with two unknowns ( $X$ and $Y$ ) are obtained, of which both unknowns can be solved.

Statistical evaluation was performed using one-way ANOVA followed by comparison among class means ${ }^{21}$ and Student's $t$ test, corrected for multiple pairwise comparisons between means. Results are expressed as the mean \pm SD.

\section{RESULTS}

In hyperthyroid rats serum $T_{4}$ was significantly higher than in the cuthyroid group, whereas serum TSH was significantly lower. In hypothyroid rats serum $\mathrm{T}_{4}$ was significantly lower and scrum TSH significantly higher than during euthyroidism (Table 1).

Thyroid hormone disappearance from medium was as published earlier. ${ }^{17,18}$ Two components of disappearance were present. The fast component (FC) is determined for a minor part by distribution through the perfusion system and the extracellular liver compartment and represents mainly uptake into the cellular compartment. The slow component (SC) represents metabolism in the liver. Two $t_{1: 2}$ values were calculated from the two components of the curve of each experiment.

\section{Fed-Liver Transport}

The $t_{1 / 2} \mathrm{FC}$ of medium disappearance using hypothyroid fed livers was not significantly different from that of cuthyroid livers, whereas with hyperthyroid fed livers it was prolonged (Table 2), representing a decreased transport of $\mathrm{T}_{3}$ into the liver. For hypothyroid fed livers, other transport

Table 2. $t_{1 / 2}$ of the FC and SC of $T_{3}$ Disappearance From the Medium Using Livers of Fed and 48-Hour-Fasted Euthyroid. Hypothyroid, and Hyperthyroid Rats (medium with $1 \%$ BSA)

\begin{tabular}{lll}
\hline & $t_{1,2} \mathrm{FC}(\mathrm{min})$ & $t_{1,2} \mathrm{SC}(\mathrm{min})$ \\
\hline Fed & & \\
$\quad$ Euthyroid $(n=7)$ & $1.32 \pm 0.08$ & $67.8 \pm 4.5$ \\
Hypothyroid $(n=8)$ & $1.40 \pm 0.09$ & $99.9 \pm 7.8^{*}$ \\
$\quad$ Hyperthyroid $(n=4)$ & $2.10 \pm 0.16^{*}$ & $65.5 \pm 5.9$ \\
Fasted & & \\
$\quad$ Euthyroid $(\mathrm{n}=3)$ & $2.55 \pm 0.2^{*}$ & $105.6 \pm 8.7^{*}$ \\
$\quad$ Hypothyroid $(n=3)$ & $2.15 \pm 0.18^{*}$ & $126.5 \pm 10.2^{*}$ \\
$\quad$ Hyperthyroid $(\mathrm{n}=5)$ & $1.41 \pm 0.10$ & $11.3 \pm 4.9$ \\
\hline NOTE. Results are the mean $\pm \mathrm{SD}$. & \\
$* P<.001$ v euthyroid fed.
\end{tabular}


Table 3. $k_{12}$ and $k_{12}$ of $T_{3}$ Transport in Livers of Fed and 48-Hour-Fasted Euthyroid, Hypothyroid, and Hyperthyroid Rats and Their Ratio (medium with $1 \%$ BSA)

\begin{tabular}{llll} 
& \multicolumn{1}{c}{$\left.\mathrm{k}_{21}(\min )^{-1}\right)$} & $\mathrm{k}_{12}(\min )$ & $\mathrm{k}_{21} / \mathrm{k}_{12}$ \\
\hline Fed & & & \\
$\quad$ Euthyroid $(\mathrm{n}=7)$ & $0.38 \pm 0.03$ & $0.14 \pm 0.02$ & $2.7 \pm 0.3$ \\
$\quad$ Hypothyroid $(\mathrm{n}=8)$ & $0.37 \pm 0.03$ & $0.14 \pm 0.03$ & $2.6 \pm 0.4$ \\
$\quad$ Hyperthyroid $(n=4)$ & $0.25 \pm 0.04^{*}$ & $0.09 \pm 0.01^{*}$ & $2.8 \pm 0.4$ \\
Fasted & & & \\
$\quad$ Euthyroid $(\mathrm{n}=3)$ & $0.20 \pm 0.02^{*}$ & $0.17 \pm 0.02$ & $1.2 \pm 0.1^{*}$ \\
$\quad$ Hypothyroid $(n=3)$ & $0.24 \pm 0.02^{*}$ & $0.17 \pm 0.01$ & $1.4 \pm 0.1^{*}$ \\
Hyperthyroid $(n=5)$ & $0.34 \pm 0.03 \dagger$ & $0.15 \pm 0.02$ & $2.4 \pm 0.3$ \\
\hline
\end{tabular}

NOTE. Results are the mean $\pm S D$.

${ }^{*} P<.001 v$ euthyroid fed.

tP $<.005 \vee$ hyperthyroid fed.

parameters such as overall $\mathrm{k}_{21}$ and $\mathrm{k}_{12}$ were also the same as for euthyroid livers. However, in hyperthyroid livers, $\mathrm{k}_{21}$ and $\mathrm{k}_{12}$ were diminished in the same direction $(P<.001)$, resulting in an unchanged ratio (Table 3 ).

A decreased $k_{21}$ in hyperthyroid livers represents a diminished fractional transport into the total liver. This could theoretically be caused by diminished transport to the extracellular, nonmetabolizing liver compartment, diminished transport into the intracellular liver compartment, or both, since $k_{21}$ represents the overall influx rate constant including transport to both intracellular and extracellular hepatic compartments. Recently, we published a method to discriminate between transport to the extracellular and intracellular liver pool. ${ }^{17.18}$ In these studies, we showed that albumin influenced only transport to the extracellular compartment of the liver and not to the intracellular compartment. To investigate transport to the extracellular and intracellular compartments of the liver, we performed liver perfusions with $1 \%$ and $4 \%$ BSA added to the medium. The results in Table 4 show that transport to the extracellular compartment of the liver was the same in livers of euthyroid and hyperthyroid rats, whereas transport to the intracellular compartment was decreased in livers of hyperthyroid rats. Transport to intracellular and extracellular compartments was not significantly different from control vallues in livers of hypothyroid rats (not shown).

\begin{tabular}{|c|c|c|c|c|}
\hline \multicolumn{5}{|c|}{ 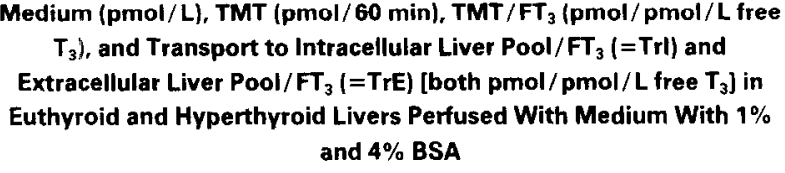 } \\
\hline & \multicolumn{2}{|c|}{ Euthyroid $(n=7)$} & \multicolumn{2}{|c|}{ Hyperthyroid $(n=4)$} \\
\hline & $1 \%$ BSA & $4^{\circ}$ & & \\
\hline hean total $T_{3}$ & $0.0 \pm 0.04$ & $3.5 \pm 0.2$ & $0.6 \pm 0.04$ & \\
\hline Mean $\mathrm{FT}_{3}$ & $13.4 \pm 0.9$ & $24.7 \pm 1.1$ & $13.5 \pm 0.9$ & $25.8 \pm 1.7$ \\
\hline TMT & $1,293 \pm 96$ & $5,995 \pm 212$ & $865 \pm 87^{*}$ & $4,974 \pm 323^{*}$ \\
\hline $\mathrm{TMT} / \mathrm{FT}_{3}$ & $96.5 \pm 6.8$ & $242.7 \pm 11.2$ & $64.1 \pm 5.7^{*}$ & $192.8 \pm 13.9^{*}$ \\
\hline $\mathrm{Trl} / \mathrm{FT}_{3}$ & $47.7 \pm 4.3$ & $47.7 \pm 4.3$ & $21.2 \pm 2.6^{*}$ & $21.2 \pm 2.6^{*}$ \\
\hline $\mathrm{TrE} / \mathrm{FT}_{3}$ & $48.7 \pm 3.3$ & $195.0 \pm 11.7$ & $42.9 \pm 4.7$ & $171.6 \pm 16.8$ \\
\hline
\end{tabular}

NOTE. Results are the mean \pm SD.

${ }^{*} P<.001 v$ euthyroid with corresponding BSA concentration.

\section{Fed-Liver Metabolism}

The $t_{1 / 2} S C$ of $T_{3}$ medium disappearance was prolonged using livers of hypothyroid rats as compared with euthyroid livers, whereas that of hyperthyroid rats was not significantly different as compared with euthyroid livers (Table 2).

After uptake into the liver cells, $T_{3}$ is conjugated to $T_{3} G$ or, before deiodination, to $\mathrm{T}_{3} S .{ }^{9} \mathrm{~T}_{3} \mathrm{G}$ normally appears mostly in the bile, $T_{3} S$ is subsequently deiodinated, and the end-product iodide is excreted mostly to the medium. ${ }^{17}$ Results of analysis of medium and bile are depicted in Table 5. In hypothyroid livers iodide excretion was diminished as compared with that in euthyroid livers $(P<.001)$; in hyperthyroid livers iodide production was not significantly different from that in euthyroid livers. Glucuronide excretion in medium and bile in euthyroid livers was the same as in hypothyroid and hyperthyroid livers. Sulfate excretion in medium and bile was diminished in hypothyroid livers $(P<.05)$ and unaffected in hyperthyroid livers. In accordance with these findings, the fractional disposal rate constant $\left(\mathrm{k}_{122}\right)$ and the integrated $T_{3}$ disposal during 60 minutes, ie, the total amount of metabolized $T_{3}$, were decreased in hypothyroid livers $(P<.001)$ and unchanged in hyperthyroid livers (Table 6 ). The availability of $T_{3}$ to the intracellular metabolizing enzymes is, among other things, influenced by the mass transfer of $T_{3}$ into the intracellular liver compartment during the experiment (see Discussion). Therefore, the disposal of $\mathrm{T}_{3}$ in the three groups has to be corrected for possible differences in intracellular mass transport (=metabolic capacity). Metabolic capacity was decreased in hypothyroid livers $(P<.001)$ and increased in hyperthyroid livers $(P<.001$; Table 6$)$.

\section{Fasted-Liver Transport}

The $t_{1 / 2}$ FC of medium disappearance using euthyroid fasted or hypothyroid fasted livers was prolonged compared with that of euthyroid fed livers, whereas with hyperthyroid fasted livers there was no significant difference (Table 2). In accordance with these findings, as compared with that in euthyroid fed livers, $k_{21}$ was diminished after fasting in

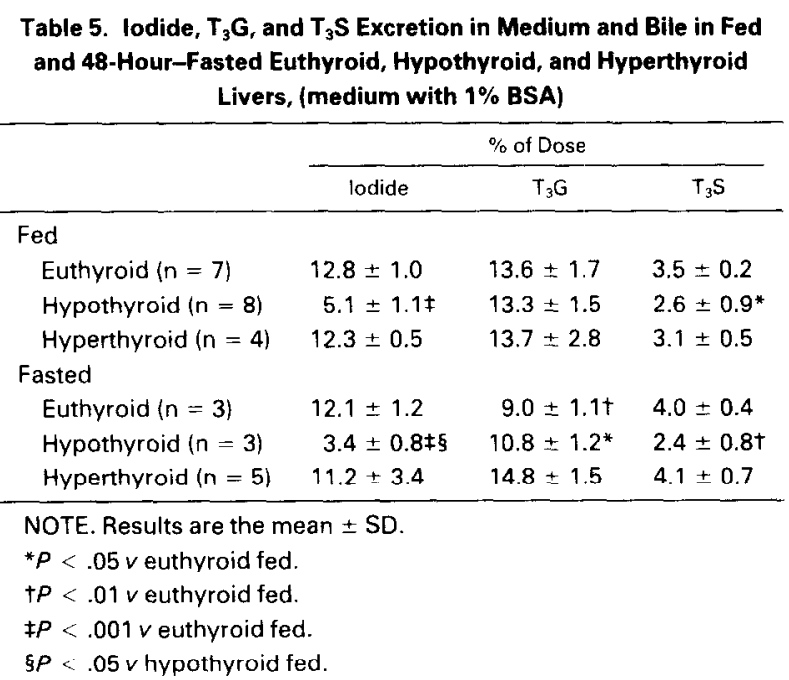


Table 6. $k_{02}$, Disposal, and Metabolic Capacity (metabolic capacity $=$ disposal/intracellular mass transfer) of Livers of Fed and 48-Hour-Fasted Euthyroid, Hypothyroid, and Hyperthyroid Rats (medium with 1\% BSA)

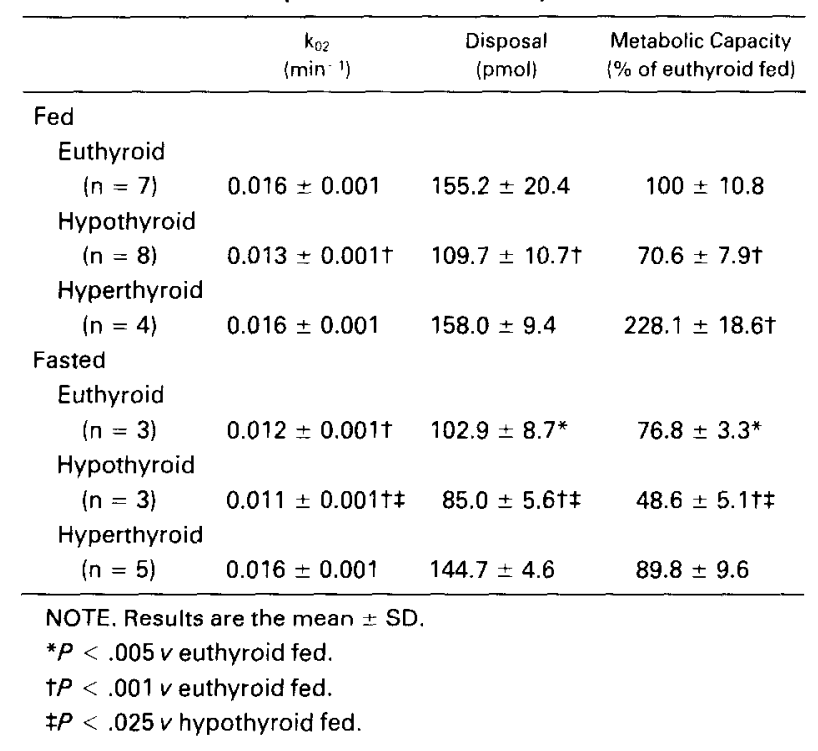

euthyroid livers $(P<.001)$ and in hypothyroid livers $(P<.001)$, whereas $\mathrm{k}_{12}$ was unchanged. Compared with that in euthyroid fed livers, both $k_{21}$ and $k_{12}$ were not significantly different in fasted hyperthyroid livers, and thus increased after fasting versus fed hyperthyroid livers $(P<.005 v$ hyperthyroid fed; Table 3$)$.

\section{Fasted-Liver Metabolism}

The $t_{1 / 2} \mathrm{SC}$ of medium disappearance using euthyroid fasted and hypothyroid fasted livers was prolonged compared with that of euthyroid fed livers, whereas with hyperthyroid fasted livers it was not significantly different (Table 2). As shown in Table 5, after fasting iodide production in euthyroid livers did not change. In hypothyroid livers, this production was diminished after fasting as compared with that in euthyroid fed livers $(P<.001)$ and hypothyroid fed livers $(P<.05)$. In hyperthyroid fasted livers the amount of iodide excreted was not significantly different from that in euthyroid fed and hyperthyroid fed livers. Glucuronide production after fasting was decreased in euthyroid livers $(P<.01 v$ euthyroid fed $)$ and in hypothyroid livers $(P<.05 v$ euthyroid fed and hypothyroid fed), but not in hyperthyroid livers. In euthyroid livers sulfate production after fasting was unchanged, and in fasted hypothyroid livers it was decreased $(P<.01 v$ e euthyroid fed, NS $v$ hypothyroid fed). whereas it was unaffected in hyperthyroid fasted livers (NS $v$ hyperthyroid fed and euthyroid fed). In Table 6 it is shown that after 48 hours of fasting $T_{3}$ disposal was decreased in euthyroid $(P<.005 \mathrm{v}$ cuthyroid fed) and in hypothyroid $(P<.001 v$ euthyroid fed, NS $v$ hypothyroid fed) livers, but not in hyperthyroid livers (NS $v$ euthyroid and hyperthyroid fed). After fasting, disposal corrected for differences in intracellular mass transport was decreased in euthyroid livers $(P<.005 v$ euthyroid fed) and in hypothyroid livers $(P<.001 v$ euthyroid fed, $P<.05 v$ hypothyroid fed), but not in hyperthyroid livers (NS $v$ euthyroid fed, decreased with $P<.001 v$ hyperthyroid fed).

Finally, in Table 7 a summary of all changes in liver transport and metabolism of $T_{3}$ during hypothyroidism and hyperthyroidism before and after 48 hours of fasting is shown.

\section{DISCUSSION}

Adaptations of thyroid hormone kinetics to a changed thyroid hormone state are not fully understood. The metabolic rate in hyperthyroid humans has, eg, been reported to be both decreased ${ }^{6}$ and increased, ${ }^{7}$ whereas in vitro investigations in rat liver homogenates pointed to an increased $\mathrm{T}_{+}$ $5^{\prime}$-deiodinase activity, ${ }^{4,5}$ attributed to changes in 5'deiodinase activity ${ }^{22-24}$ and in cytosolic cofactor. ${ }^{24}$ In hypothyroid humans, the fractional conversion rate of $T_{4}$ is increased 7.8 .25 ; however, studies using rat liver showed decreased hepatic $5^{\prime}$-deiodinase activities. ${ }^{23}$ An increased fractional conversion rate of $T_{+}$may be explained by increased deiodinase activity in the brain during hypothyroidism. ${ }^{26}$

In most in vitro measurements, the role of active transport over the cell membrane was not considered. Studies in a human subject, rat hepatocytes, and perfused rat liver have shown transport of thyroid hormones to be ratelimiting in total cellular uptake and metabolism. ${ }^{16.27 .28}$

\section{Fed Livers}

In livers of hypothyroid rats transport parameters are not significantly altered, ie, $k_{21}$ and $k_{12}$ are not significantly different compared with those of euthyroid livers. As for metabolism, iodide production is diminished in hypothyroid livers. When only deiodination is inhibited in liver $T_{3}$ metabolism, the $T_{3} S$ concentration will increase because $T_{3}$ has to be sulfated before it is deiodinated. ${ }^{9}$ This phenomenon was found in livers perfused with medium to which propylthiouracil (PTU) was added ${ }^{15}$; iodide production from $T_{3}$ was strongly inhibited by $P T U$, while $T_{3}$ conjugates accumulated.

In hypothyroid livers $T_{3} S$ production was decreased as compared with that in control livers. This decrease, instead of the expected increase due to the impaired deiodination.

Table 7. Changes in Transport and Metabolism of $T_{3}$ in Livers of Euthyroid, Hypothyroid, and Hyperthyroid Rats

\begin{tabular}{|c|c|c|}
\hline & Transport & Metabolism \\
\hline \multicolumn{3}{|l|}{ Fed } \\
\hline Euthyroid & - & - \\
\hline Hypothyroid & - & $\vdots$ \\
\hline Hyperthyroid & $\downarrow$ & 1 \\
\hline \multicolumn{3}{|l|}{ Fasted } \\
\hline Euthyroid & $\downarrow$ & $\downarrow$ \\
\hline Hypothyroid & $\downarrow$ & $: 1$ \\
\hline Hyperthyroid & - & - \\
\hline
\end{tabular}

NOTE. - , no changes $v$ euthyroid fed; $\downarrow$, decreased $v$ euthyroid fed; $\uparrow$, increased $v$ euthyroid fed. 
points to an inhibited sulfation as well. This is in accordance with a decreased disposal in hypothyroid livers, whereas it was not present in fed livers after PTU.

It has been reported that nuclear $T_{3}$ in euthyroid, hypothyroid, and hyperthyroid livers is derived mainly from plasma, despite present local $T_{4}$ to $T_{3}$ conversion. ${ }^{3,29}$ In hypothyroidism total and free plasma $T_{3}$ concentrations are decreased, thereby decreasing the supply of hormone to the liver. In case of unchanged transport but decreased metabolism, the rate of $\mathrm{T}_{3}$ degradation in the liver will decrease (metabolic capacity is $70 \%$ of that of euthyroid fed livers) and more intracellular $T_{3}$ will be available for binding to the nuclear receptors, since the intracellular hormone concentration is determined by (1) the plasma (medium) flow rate, (2) plasma (medium) concentration of hormone and hormone-binding proteins, (3) rate constant for hormone dissociation from its binding proteins, (4) rebinding to its binding proteins, (5) influx rate constant into the cell, (6) efflux rate constant, and (7) metabolic rate constant. ${ }^{30}$ Since the first four factors are constant in our liver perfusion system, only the ratio of $k_{21}$ to $k_{12}$ and the $k_{02}$ determine the intracellular hormone concentration. The observed effects of hypothyroidism on liver uptake and metabolism of $T_{3}$ might favor tissue euthyroidism despite the hypothyroid state.

In hyperthyroid livers, the ratio of $k_{21}$ to $k_{12}$ was unchanged. However, both $\mathrm{k}_{21}$ and $\mathrm{k}_{12}$ are decreased as compared with those in euthyroid livers, whereas the medium pool is the same for both livers in our liver perfusion system, leading to a decreased TMT into the intracellular liver compartment. The cause of the decreased TMT and $k_{21}$ is as yet not known. The synthesis of hepatic mitochondrial adenosine triphosphate (ATP) is increased during hyperthyroidism. However, in vivo the energy state is reduced in the hyperthyroid liver, reflecting a new balance between increased ATP synthesis and even more increased consumption. ${ }^{31}$ This reduced ATP availability may be the cause of the decreased transport of thyroid hormone into the hyperthyroid liver. Jennings et al, ${ }^{32}$ concerning $T_{4}$ uptake and metabolism in the perfused rat liver, also found a decrease in the hepatic uptake of $\mathrm{T}_{4}$ in thyrotoxicosis opposite to an increase in deiodination, in agreement with our findings. With regard to increased $T_{3}$ conjugation in hyperthyroid livers (at least when corrected for transport into the metabolizing pool, which is decreased in hyperthyroid livers), at present there are to our knowledge no other studies published in which hepatic conjugation of thyroid hormones during hyperthyroidism has been investigated. However, many other hepatic enzymatic processes, including, eg, glucuronidation of several substances, show an increased activity during hyperthyroidism. ${ }^{33-36}$ The attenuated transport together with the increased metabolism during hyperthyroidism protects the liver at least partially against tissue hyperthyroidism.

\section{Fasted Livers}

Fasting results in a decrease of both transport into the intracellular liver compartment and subsequent metabo- lism of $\mathrm{T}_{3}$ in cuthyroid perfused rat livers, as previously described, ${ }^{17}$ probably due to a decrease of intracellular ATP after fasting. ${ }^{37}$ This results in a decrease of the metabolic capacity to $77 \%$ of euthyroid fed livers. We did not correct for a decrease in liver weight after 48 hours' fasting, since the weight loss is mainly due to glycogen depletion and does not play an active role in thyroid hormone transport and metabolism. ${ }^{18}$ In hypothyroid fasted livers both $\mathrm{k}_{21}$ and metabolism are decreased as compared with that in euthyroid and hypothyroid fed livers, whereas $\mathrm{k}_{12}$ was not significantly changed. Compared with euthyroid fasted livers, because of an even further decrease of metabolism after fasting in the hypothyroid liver (metabolic capacity is $50 \%$ of that of euthyroid fed livers), the availability of liver $T_{3}$ to nuclear binding may be increased, which is favorable during hypothyroidism. A marked overlap between the changes in the rat hepatic inRNA activity profile induced by either hypothyroidism or starvation has been reviewed. ${ }^{38}$ In our study, we were able to discriminate between the fasted euthyroid and fed hypothyroid state of the livers on the basis of differences in transport (Table 3) and in iodide and glucuronide production (Table 5). However, according to Mariash and Oppenheimer ${ }^{38}$ hypothyroidism and fasting apparently work in the same direction with regard to the metabolic state of the liver, in accordance with the fact that after fasting in the hypothyroid liver $\mathrm{I}_{3}$ metabolism is further decreased compared with that in the hypothyroid fed liver. Transport, which is unaffected in the hypothyroid fed liver, is also decreased after fasting. It must be noted that the results of this study apply to the rat, a specics that becomes hypothyroid after fasting beyond 48 hours. ${ }^{24.39}$ Although our rats are fasted for only 48 hours, one has to be careful in extrapolating these results directly to other species, including humans.

In fasted hyperthyroid livers, transport is increased as compared with that in fed hyperthyroid livers. In other words, the decrease in transport effected by hyperthyroidism in fed livers is abolished by fasting. Delineating the mechanisms of this effect awaits further investigation, especially on factors regulating cellular transport activity. Metabolic capacity, which is increased in fed hyperthyroid livers, is decreased with additional fasting and comparable to $T_{3}$ metabolism in the fed euthyroid liver. Thus, alterations in transport and metabolism induced by hyperthyroidism are normalized by fasting. Our data therefore suggest that in fact the fasted "hyperthyroid" rats may have become euthyroid. These findings are in accordance with the fact that hypcrthyroidism and fasting have an opposite cffect on patterns of rat hepatic mRNA activity. ${ }^{38}$ So, also during fasting the availability of liver $T_{3}$ to nuclear binding shows adaptations during hypothyroidism and hyperthyroidism, which are favorable during these conditions.

These changes might favor tissue euthyroidism, despite the altered thyroid and nutritional state, and can therefore be seen as adaptation mechanisms to these altered states at the tissue level. 


\section{REFERENCES}

1. LoPresti JS, Warren DW, Kaptein EM, et al: Urinary immunoprecipitation method for estimation of thyroxine to triiodothyronine conversion in altered thyroid states. J Clin Endocrinol Metab 55:666-670, 1982

2. Dratman MB, Crutchfield FL, Gordon JT, et al: Iodothyronine homeostasis in rat brain during hypo- and hyperthyroidism. Am J Physiol 245:E185-E193. 1983

3. Van Doorn J, Roelfsema F, van der Heide D: Contribution from local thyroxine to intracellular 3,5,3'-triiodothyronine conversion in several organs of hypothyroid rats at isotope equilibrium. Acta Endocrinol (Copenh) 101:386-392, 1982

4. Kaplan MM, Utiger RD: Iodothyronine metabolism in liver and kidney homogenates from hyperthyroid and hypothyroid rats. Endocrinology 103:156-161, 1978

5. Grussendorf $M$. Hufner $M$ : Induction of the thyroxine to triiodothyronine converting enzyme in rat liver by thyroid hormones and analogs. Clin Chim Acta 80:61-66, 1977

6. Shimizu TC, Pittman CS, Chambers JJB, et al: The effect of thyroxine on the peripheral conversion rate of thyroxine to triiodothyronine in man, in Robbins $J$, Braverman LE (eds): Thyroid Research: Proceedings of the Seventh International Thyroid Conference. New York, NY, American Elsevier, 1976, p 263

7. Maguire SB, Dennehy A, Cullen MJ: The effect of thyrotoxicosis and hypothyroidism on the extrathyroidal conversion of thyroxine to triioduthyronine in man, in Robbins J, Braveman LE (eds): Thyroid Research: Proceedings of the Seventh International Thyroid Conference. New York. NY. American Elsevier, 1976, p 259

8. Inada M, Kanji K. Kurata S. et al: Estimation of thyroxine and triiodothyronine distribution and of the conversion rate of thyroxine to triiodothyronine in man. J Clin Invest 55:1337-1344, 1975

9. Leonard JL. Visser TJ: Biochemistry of deiodination. in Hennemann G (ed): Thyroid Hormone Metabolism. New York, NY, Dekker, 1986, pp 189-229

10. Visser TJ, Van der Does-Tobe I, Docter R, et al: Conversion of thyroxine into triiodothyronine by rat liver homogenate. Biochem J 150:489-493. 1975

11. Visser TJ, Kaplan MM, Leonard JL, et al: Evidence for two pathways of iodothyronine $5^{\circ}$-deiodination in rat pituitary that differ in kinetics, propylthiouracil sensitivity, and response to hypothyroidism. J Clin Invest 71:992-1002. 1983

12. Krenning EP, Docter R, Bernard HF, et al: Characteristics of active transport of thyroid hormone into rat hepatocytes. Biochim Biophys Acta 676:314-320, 1981

13. Krenning EP, Docter $\mathbf{R}$, Bernard HF, et al: Decreased transport of thyroxine $\left(T_{4}\right), 3,3^{\prime}, 5$-triiodothyronine $\left(T_{3}\right)$ and $3,3^{\prime}, 5^{\prime}$ triiodothyronine $\left(\mathrm{rT}_{3}\right)$ into rat hepatocytes in primary culture due to a decrease of cellular ATP content and various drugs. FEBS Lett 140:229-233, 1982

14. Krenning EP, Docter R, Bernard HF, et al: Active transport of triiodothyronine $\left(\mathrm{T}_{3}\right)$ into isolated rat liver cells. FEBS Lett 91:113-116, 1978

15. De Jong M. Docter R, Van der Hoek HJ, et al: Different effects of amiodarone on transport of $T_{4}$ and $T_{3}$ into the perfused rat liver. Am J Physiol 266:E44-E49, 1994

16. Hennemann G, Vos RA, De Jong $M$, et al: Decreased peripheral $T_{3}$ production from $T_{4}$ : A syndromc of impaircd thyroid hormone activation due to transport inhibition of $T_{4}$ into $T_{3}$ producing tissues. J Clin Endocrinol Metab 77:1431-1435, 1993

17. Docter R, de Jong M, van der Hoek HJ, et al: Development and use of a mathematical two pool model of distribution and metabolism of $3.3^{\prime} .5$-triiodothyronine in a recirculating rat liver perfusion system: Albumin does not play a role in cellular transport. Endocrinology 126:451-459, 1990

18. De Jong M, Docter R, van der Hoek HJ, et al: Transport of $\mathrm{T}_{3}$ and subsequent metabolism in the perfused rat liver are inhibited by fasting. Endocrinology 131:463-470, 1992

19. Meijer KF, Keulemans K. Mulder GJ: Isolated perfused rat liver technique. Methods Enzymol 77:81-93, 1981

20. Sterling K, Brenner MA: Free thyroxine in human serum: Simplified measurement with the aid of magnesium precipitation. $J$ Clin Invest 45:153-163, 1966

21. Snedecor GW. Cochran WG: One-way classifications. Analysis of variance, in Statistical Methods (ed 6). Ames, IA. The Iowa University Press, 1967, pp 258-298

22. Harris ARC, Fang SL, Hinderfeld $L$, et al: The role of sulphydryl groups on the impaired hepatic triiodothyronine generation from thyroxine in the hypothyroid. starved, fetal, and neonatal rodent. J Clin Invest 63:516-522. 1979

23. Kaplan MM: Changes in the particulate subcellular component of hepatic thyroxine- 5 -monodeiodinase in hyperthyroid and hypothyroid rats. Endocrinology 105:548-554, 1979

24. Balsam A, Sexton F, Ingbar SH: The influence of fasting and the thyroid state on the activity of thyroxine 5 '-monodeiodinase in rat liver: A kinetic analysis of microsomal formation of triiodothyronine from thyroxine. Endocrinology 108:472-477, 1981

25. Lum SMC. Nicoloff IT, Spencer CA. et al: Peripheral tissue mechanism for maintenance of serum triiodothyronine values in a thyroxine-deficient state in man. J Clin Invest 73:570-575, 1984

26. Kaplan MM, Yaskoski KA: Effects of congenital hypothyroidism and partial and complete food deprivation on phenolic and tyrosyl ring iodothyronine deiodination in rat brain. Endocrinology 110:761-767, 1982

27. Hennemann G, Krenning EP. Polhuis M, et al: Carriermediated transport of thyroid hormones into rat hepatocytes is rate limiting in total cellular uptake. Endocrinology 119:1870-1872, 1986

28. Jennings AS, Ferguson DC, Utiger RD: Regulation of the conversion of thyroxine to triiodothyronine in the perfused rat liver. J Clin Invest 64:1614-1623, 1979

29. Van Doorn J, Van der Heide D. Roelfsema F: The contribution of local thyroxine monodeiodination to intracellular 3.5 .3 'triiodothyronine in several tissues of hyperthyroid rats at isotopic equilibrium. Endocrinology 115:174-182, 1984

30. Mendel CM. Cavalieri RR. Weisiger RA: Uptake of the thyroxine by the perfused rat liver: Implications for the free hormone hypothesis. Am J Physiol 255:E1 10-E119, 1988

31. Muller MJ, Seitz HJ: Thyroid hormone action on intermediary metabolism. I. Respiration, thermogenesis and carbohydrate metabolism. Klin Wochenschr 62:11-18, 1984

32. Jennings AS, Crutchfield FL, Dratman MB: Effect of hypothyroidism and hyperthyroidism on triiodothyronine production in perfused rat liver. Endocrinology 114:992-997. 1984

33. Kosuge T, Beppu T, Kodama T, et al: Serum bile acid profile in thyroid dysfunction and effect of medical treatment. Clin Sci 73:425-429, 1987

34. Muller MJ, Seitz HJ: Thyroid hormone action on intermediary metabolism. II. Lipid metabolism in hypo- and hyperthyroidism. Klin Wochenschr 62:49-55, 1984

35. Fernandez V, Simizu K, Barros SB, et al: Effects of hyperthyroidism on rat liver glutathione metabolism: Related enzymes' activities, efflux and turnover. Endocrinology 129:85-91, 1991

36. O'Connor P, Feely J: Clinical pharmacokinetics and endocrine disorders. Therapeutic implications. Clin Pharmacokinet 13:345-364, 1987 
37. Cunningham CC, Malloy CR, Radda GK: Effect of fasting and acute ethanol administration on the energy state of in vivo liver as measured by ${ }^{31}$ P.NMR spectroscopy. Biochim Biophys Acta $885: 12-22,1986$

38. Mariash $\mathrm{CN}$, Oppenheimer JH: Interaction of thyroid hor- mone and nutritional signals on thyroid hormone action. Mol Cell Endocrinol 43:3-13, 1985

39. O'Mara BA, Dittrich W, Lauterio TJ, et al: Pretranslational regulation of type $I^{\prime} 5^{\prime}$-deiodinase by thyroid hormones and in fasted and diabetic rats. Endocrinology 133:1715-1723, 1993 